\title{
Microsurgery of Cerebral Aneurysm: Epidemiological Profile
}

\section{Microcirurgia do aneurisma cerebral: Perfil epidemiológico}

\author{
Luiz Roberto Tomasi Ribeiro $^{10}$ Rubens Thadeu Mangilli De Menezes ${ }^{20} \quad$ Kristian Madeira ${ }^{3}$ \\ Carlos Fernando dos Santos Moreira2 ${ }^{2}$
}

1 Hospital Cristo Redentor, Porto Alegre, RS, Brazil

Address for correspondence Carlos Fernando dos Santos Moreira,

${ }^{2}$ Hospital São José, Criciúma, SC, Brazil

${ }^{3}$ Department of Medicine, Universidade do Extremo Sul Catarinense, Criciúma, SC, Brazil \begin{abstract}
MD, Curso de Medicina, Universidade do Extremo Sul Catarinense, Av. Universitária, 1105, Criciúma - SC, Brasil, CEP - 88806-000 (e-mail: cfernandomoreira@hotmail.com).
\end{abstract}

Arq Bras Neurocir 2020;39(2):101-107.

\begin{abstract}
Keywords

- intracranial aneurysm

- microsurgery

- subarachnoid hemorrhage
\end{abstract}

Resumo
Objectives Intracranial aneurysm consists of localized dilatation of the vascular wall. Its importance includes the fearsome event of rupture and subarachnoid hemorrhage, which presents high morbimortality rates. The present study aimed to analyze the profile and clinical outcome of patients submitted to the microsurgical approach of cerebral aneurysm in the city of Criciúma, state of Santa Catarina, Brazil, from 2015 to 2018.

Methods A retrospective observational study was performed, with secondary data collection and a quantitative approach of 47 charts.

Results A predominance of females ( $74.5 \%)$ and a mean age of 53 years old $(53.53 \pm 9.64)$ was observed. The middle cerebral artery was the most affected vessel (36.2\%), with the highest percentage of aneurysms being between $2.1 \mathrm{~mm}$ and $7.0 \mathrm{~mm}$ (65.9\%). There was a correlation between consciousness level and classification on the Hunt-Hess $(\mathrm{HH})$ scale. Patients with Glasgow Coma Scale (GCS) $>7$ points had a better prognostic score in the $\mathrm{HH}$ scale, and those with GCS $\leq 7$ points had a worse prognostic score in the HH scale.

Conclusions The present study observed the presence of important risk factors for cerebral aneurysm formation, such as gender, age, smoking, and systemic arterial hypertension. The present study can measure a correlation of the level of consciousness with the $\mathrm{HH}$ classification.

Objetivos O aneurisma cerebral consiste na dilatação localizada na parede vascular. Sua importância compreende o evento de ruptura e hemorragia subaracnóidea, tal evento com altas taxas de morbimortalidade. A presente pesquisa se propôs a analisar

\section{Introduction}

Cerebrovascular diseases are increasingly common. In 2015, 593,015 cases of cerebrovascular diseases were found in Brazil. $^{1}$ According to recent estimates, there is a tendency toward a progressive increase in the number of deaths from cerebrovascular diseases, and it is estimated that by 2030 the percentage will reach $12.1 \%$ of the world mortality. $^{2}$

Cerebral aneurysm consists of localized dilation of the vascular wall which, when ruptured, generates subarachnoid hemorrhage $(\mathrm{SAH}){ }^{3}$ Most cerebral aneurysms are asymptomatic for a lifetime or until they rupture, and received

September 27, 2019

accepted

January 15, 2020

published online

April 6, 2020
DOI https://doi.org/

10.1055/s-0040-1708892. ISSN 0103-5355.
Copyright (c) 2020 by Thieme Revinter

Publicações Ltda, Rio de Janeiro, Brazil
License terms

(요 (1) $\Theta$ 


\section{Descritores}

- aneurisma intracraniano

- microcirurgia

- hemorragia subaracnóidea o perfil e o desfecho clínico de pacientes submetidos a abordagem microcirúrgica de aneurisma cerebral na cidade de Criciúma, Santa Catarina, Brasil, de 2015 a 2018. Métodos Foi realizado estudo observacional retrospectivo, com coleta de dados secundários e abordagem quantitativa de 47 prontuários.

Resultados Foi observada uma predominância do sexo feminino (74,5\%) e uma média de idade de 53 anos $( \pm 9,64)$. A artéria cerebral média foi o vaso mais acometido (36,2\%), com a maior porcentagem dos aneurismas situando-se entre $2,1 \mathrm{~mm}$ a $7,0 \mathrm{~mm}(65,9 \%)$. Houve uma correlação entre o nível de consciência dos pacientes e a classificação dos mesmos na escala de Hunt-Hess $(\mathrm{HH})$. O paciente com Escala de Coma de Glasgow (GCS) > 7 pontos obteve uma classificação de melhor prognóstico em $\mathrm{HH}$ e aquele com GCS $\leq 7$ pontos obteve uma classificação de pior prognóstico em $\mathrm{HH}$.

Conclusões O presente estudo observou a presença de fatores de risco importantes para a formação do aneurisma cerebral, como gênero, idade, tabagismo e hipertensão arterial sistêmica. O presente estudo pode aferir uma correlação do nível de consciência com a classificação de HH. may progress to $\mathrm{SAH}$, one of the serious events of its rupture. $^{4,5}$

Subarachnoid hemorrhage has a high mortality of 25 to $50 \%$; $^{6}$ out of those, $12 \%$ die before getting medical attention. Five years after the episode, this complication can reach an approximate mortality rate of $70 \%$. Its worldwide incidence is estimated at 9.1 per 100,000 inhabitants/year (95\% confidence interval $[\mathrm{CI}]: 8.8-9.5) .{ }^{7}$ Brain aneurysms occur in $\sim 1$ to $2 \%$ of the population. ${ }^{6}$ They are more common in females in a $2: 1$ ratio, $^{8}$ and their prevalence increases with age. Only $\sim 20 \%$ of cases occur below the age of 45 years old. ${ }^{9}$

Not all patients are elected for aneurysmal clipping; therefore, clinical and imaging methods are used to highlight the size and location of the lesion and their likelihood of benefit from surgical treatment. ${ }^{5}$ Noncontrast computed tomography (CT) is a good imaging test for the initial evaluation of a patient with suspected SAH. It has a detection rate close to $100 \%$ in the first 3 days after the onset of symptoms, but falling to $50 \%$ between 5 and 7 days later. ${ }^{6}$ Cerebral angiography (DSA) is considered the gold standard for the diagnosis of cerebral aneurysm, because with this exam we can increase the detection rate of aneurysms smaller than $3 \mathrm{~mm}$, which CT and MRI are not accurate in evaluating. Cerebral angiography is indicated for patients with high suspicion of SAH on whom an aneurysm was not evidenced by traditional methods. ${ }^{10}$

The intensity of the meningeal inflammatory reaction, the severity of the neurological deficit and the presence or absence of significant associated comorbidities should provide the best clinical criterion for estimating the surgical risk, which is the objective of the Hunt-Hess (HH) scale. ${ }^{11}$ When classified as $\mathrm{HH}$ I or II, patients are eligible for surgery as soon as the aneurysm is diagnosed and the gold standard technique for aneurysm treatment is its clipping. ${ }^{12}$ This consists of exposure of the aneurysmal sac via craniotomy and obliteration of its circulation wall by means of single or multiple clips. This approach has good postoperative results with an aneurysm obliteration rate in $93 \%$ of cases, as well as a lower percentage of reintervention. ${ }^{13}$ To those who were not elected for surgery at the time of the diagnosis, it is recommended a conservative management to achieve a clinical improvement (until the patient has an HH I or II) for subsequent aneurysm clipping.

Given the importance of brain aneurysm microsurgery in the context of neurosurgery and the need to evaluate the epidemiological profile of patients undergoing the procedure in the southern state of Santa Catarina population, this research aimed to analyze the profile and clinical outcome of patients undergoing the microsurgical approach of cerebral aneurysm in the city of Criciúma from 2015 to 2018.

\section{Methods}

The present study has been approved by the Ethics and Research Committee of the Universidade do Extremo Sul Catarinense (UNESC), under the approval number 2.857.653 and by the Ethics and Research Committee of the São José Hospital de Criciúma, state of Santa Catarina, Brazil, under the approval number 2.890.169.

This is a retrospective observational study with a quantitative approach and secondary data collection. The sample in question was obtained through analysis of medical records, comprising 47 patients in the study, which corresponds to patients undergoing brain aneurysm microsurgery procedure in public and private nosocomial institutions of the microregion of Criciúma, state of Santa Catarina, Brazil, in the period from January 1, 2015 to December 31, 2018. Medical records with improper filling and those diagnosed with nonaneurysmal SAH have been excluded from the study. Endovascular treatment was not included in our study and patients were not submitted to another kind of treatment, except microsurgical or conservative, due to unavailability during the data collection period. 
The following variables were analyzed: patient age at diagnosis, gender, self-reported race, previous risk factors (Systemic arterial hypertension [HAS], autosomal dominant polycystic kidney disease [ADPKD], Ehlers-Danlos syndrome type IV, Marfan syndrome, elastic pseudoxanthoma, dyslipidemia, alcoholism, physical inactivity and illicit drug use), past history of cerebral aneurysm, family history of cerebral aneurysm, previous history of SAH, previous history of traumatic brain injury [TBI], preoperative and postoperative Glasgow coma scale (3 to 15), Fisher scale (in degree, from I to IV), preoperative and postoperative Hunt and Hess scale (I, II, III, IV or V), type of aneurysm (dissecting, fusiform, mycotic, traumatic, saccular), vessel affected by the aneurysm and aneurysm size in millimeters.

The collected data were analyzed using the IBM SPSS Statistics for Windows, Version 23.0 (IBM Corp., Armonk, NY, USA) spreadsheets. Quantitative variables are expressed as mean and standard deviation (SD) and qualitative variables as frequency and percentage.

The inferential analysis was performed with a significance level $\alpha=0.05$ and, therefore, 95\% confidence. To assess the distribution of quantitative variables for normality, the Shapiro-Wilk test was used. The investigation of the homogeneity of quantitative data was performed by the Levene test.

The comparison of the mean values of the quantitative variables between the categories of the dichotomous qualitative variables was performed by applying the Student t-test for unrelated data, while the related data were investigated by applying the Wilcoxon t-test.

The comparison of the mean values of the quantitative variables between the categories of the polytomous qualitative variables was performed by applying the analysis of variance (ANOVA) test, with subsequent least square difference (LSD) post hoc.

The association between the qualitative variables was investigated by applying the Likelihood Ratio test with subsequent residue analysis in cases with statistical significance.

\section{Results}

We analyzed 47 medical records of patients undergoing brain aneurysm microsurgery. Out of these records, none were excluded from the sample.

Out of the 47 patients, 35 (74.5\%) were female. The average age of the patients was $53.53 \pm 9.64$ years old. Out of the patients submitted to cerebral aneurysm microsurgery, $51.1 \%$ had a previous diagnosis of hypertension, and only $6.4 \%$ had a previous history of cerebral aneurysm. As for the lifestyle of the patients, $21.3 \%$ were smokers at the time they underwent microsurgery, $6.4 \%$ were former smokers, $2.1 \%$ were alcoholics and $4.3 \%$ were addicted cocaine users (-Table 1).

In the preoperative evaluation of the patients, there was a predominance of HH II (36.2\%), followed by HH I (27.7\%), IV (17.0\%), III (12.8\%) and V (6.4\%). In the postoperative evaluation, there was a higher prevalence of patients classified as HH I (40.4\%), followed by HH III (25.5\%), IV (19.1\%), V (8.5\%) and II (6.4\%). It can be observed that there was no statistically
Table 1 Epidemiological profile of patients undergoing cerebral aneurysm microsurgery

\begin{tabular}{|c|c|}
\hline & Mean \pm SD, $\boldsymbol{n}(\%)$ \\
\hline & $n=47$ \\
\hline Age (years old) & $53.53 \pm 9.64$ \\
\hline \multicolumn{2}{|l|}{ Gender } \\
\hline Female & $35(74.5)$ \\
\hline Male & $12(25.5)$ \\
\hline \multicolumn{2}{|l|}{ Comorbidities } \\
\hline HAS & $24(51.1)$ \\
\hline Smoking & $10(21.3)$ \\
\hline Ex-Smoking & $3(6.4)$ \\
\hline Previous aneurysm & $3(6.4)$ \\
\hline Addict & $2(4.3)$ \\
\hline Alcoholism & $1(2.1)$ \\
\hline
\end{tabular}

Abbreviations: SD, standard deviation; HAS, systemic arterial hypertension.

Source: Search data, 2019.

significant difference in the HH classification, when comparing the preoperative with the postoperative.

Preoperative Glasgow Coma Scale (GCS) analysis showed a predominance of GCS level of consciousness $>7$ (80.9\%). In the first postoperative period without sedation, the GCS rate $>7$ was $78.7 \%$. The preoperative mean GCS was 12.19 ( \pm 4.24$)$, and the postoperative average was 11.34 ( \pm 3.70$)$. It was observed that there was no statistically significant difference in GCS when comparing the with the postoperative ( $\mathbf{- T a b l e ~} \mathbf{2}$ ).

Regarding the Fisher scale, which was verified in the medical records of patients undergoing aneurysmal microsurgery, there was a predominance of grade IV (44.7\%) compared with grade II (23.4\%), grade I (17.0\%) and grade III (14.9\%) (-Figure 1).

Table 2 Pre-and postoperative clinical scales of patients undergoing cerebral aneurysm microsurgery

\begin{tabular}{|c|l|l|l|}
\hline \multirow{4}{*}{} & \multicolumn{2}{|l|}{ Mean \pm SD, $\boldsymbol{n}$ (\%) } & \multirow{2}{*}{-value $^{\dagger}$} \\
\cline { 2 - 3 } & Preoperative & Postoperative & \\
\hline Hunt-Hess & \multirow{2}{*}{0.465} \\
\hline I & $13(27.7)$ & $19(40.4)$ & \\
\hline II & $17(36.2)$ & $3(6.4)$ & \\
\hline III & $6(12.8)$ & $12(25.5)$ & \\
\hline IV & $8(17.0)$ & $9(19.1)$ & \multirow{2}{*}{0.112} \\
\hline V & $3(6.4)$ & $4(8.5)$ & \\
\hline GCS & $12.19 \pm 4.24$ & $11.34 \pm 3.70$ & \\
\hline$\leq 7$ & $9(19.1)$ & $10(21.3)$ & \\
\hline$>7$ & $38(80.9)$ & $37(78.7)$ & \\
\hline
\end{tabular}

Abbreviations: SD, standard deviation; GCS, Glasgow Coma Scale. †Value obtained after applying the Wilcoxon t-test.

Source: Search data, 2019. 


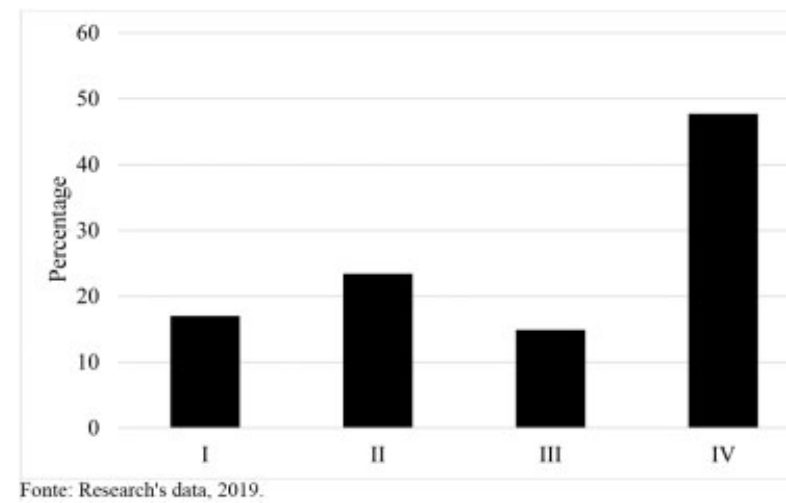

Fig. 1 Fisher tomographic scale.

Regarding the size of the aneurysmal sac, most (65.9\%) of the study patients had an aneurysm between 2.1 and $7.0 \mathrm{~mm}$. Aneurysms between 7.1 and $12.0 \mathrm{~mm}$ accounted for $21.3 \%$ of cases, while small aneurysms ( $\leq 2 \mathrm{~mm}$ ) constituted $6.4 \%$ of the sample. Aneurysmal sacs $>12.1 \mathrm{~mm}$ were evidenced in only $6.4 \%$ of the patients. The middle cerebral artery (MCA) (36.2\%) was the most frequently affected vessel in the study, followed by the internal carotid artery (ICA) (21.3\%) and the anterior communicating artery (ACoA) (21.3\%). Other vessels were observed less frequently: the ophthalmic artery (8.5\%), the posterior communicating artery (PCoA) (8.5\%), the posterior cerebral artery (PCA) (2.1\%), and the basilar artery (2.1\%). Regarding the most affected arterial system, $87.3 \%$ of the aneurysms were located in the carotid system (also known as anterior system) (-Table $\mathbf{3}$ ).

Table 3 Dimension and topography of aneurysms submitted to microsurgery

\begin{tabular}{|c|c|}
\hline & $n(\%)$ \\
\hline \multicolumn{2}{|l|}{ Size $(\mathrm{mm})$} \\
\hline Up to $2 \mathrm{~mm}$ & $3(6.4)$ \\
\hline Between 2.1 and $7.0 \mathrm{~mm}$ & $31(65.9)$ \\
\hline Between 7.1 and $12.0 \mathrm{~mm}$ & $10(21.3)$ \\
\hline Between 12.1 and $25.0 \mathrm{~mm}$ & $2(4.3)$ \\
\hline Greater than $25.1 \mathrm{~mm}$ & $1(2.1)$ \\
\hline \multicolumn{2}{|l|}{ Topography } \\
\hline Middle cerebral artery & $17(36.2)$ \\
\hline Internal carotid artery & $10(21.3)$ \\
\hline Anterior cerebral artery & $10(21.3)$ \\
\hline Ophthalmic artery & $4(8.5)$ \\
\hline Posterior communicating artery & $4(8.5)$ \\
\hline Posterior cerebral artery & $1(2.1)$ \\
\hline Basilar artery & $1(2.1)$ \\
\hline \multicolumn{2}{|l|}{ System } \\
\hline Carotid (Anterior) & $41(87.3)$ \\
\hline Vertebro-Basilar (Posterior) & $6(12.7)$ \\
\hline
\end{tabular}

Source: Search data, 2019.
Preoperative patients with a HH IV or V classification obtained, after residual analysis ( $p<0.05$ ), a correlation with a worse GCS score $(\leq 7)$ with results of $66.7 \%$ and $33.3 \%$, respectively. Those who were preoperatively classified as $\mathrm{HH}$ I or II had, after residual analysis $(p<0.05)$, a relationship with higher GCS scores ( $>7$ ) with results of $34.2 \%$ and $44.7 \%$, respectively. The correlation of preoperative patients between HH III and GCS score ( $\leq 7$ or $>7$ ) was not statistically significant after residual analysis.

Postoperative patients with a $\mathrm{HH}$ IV or $\mathrm{V}$ classification obtained, after residual analysis $(p<0.05)$, a correlation with a worse GCS score $(\leq 7)$ of $60 \%$ and $40 \%$, respectively. Those who were preoperatively classified as HH I or III obtained, after residual analysis $(p<0.05)$, a relationship with higher GCS scores ( $>7$ ) with results of $51.4 \%$ and $32.4 \%$, respectively. The correlation of postoperative patients between HH II and GCS score $(\leq 7$ or $>7$ ) was not statistically significant after residual analysis ( - Table $\mathbf{4}$ ).

In the analysis of the vascular system affected by the aneurysm in relation to the Fisher tomographic scale presented at the time of diagnosis, 41 patients were in the affected anterior system group and 6 patients were in the affected posterior system group. Out of those with an anterior system aneurysm, 14.6\% had Fisher I, 26.8\% had Fisher II, 14.6\% had Fisher III, and 43.9\% had Fisher IV. Regarding those with a posterior system aneurysm, 33.3\% had Fisher I, 0\% had Fisher II, 16.7\% had Fisher III and 50\% had Fisher IV. No correlation between vascular system affected by aneurysm and Fisher tomographic scale was statistically significant (-Table 5).

There is a relationship between $\mathrm{AH}$ and age at the time of aneurysm diagnosis: hypertensive patients have a higher

Table 4 Correlation between Glasgow and Hunt-Hess before and after surgery

\begin{tabular}{|c|c|c|c|}
\hline & \multicolumn{2}{|c|}{ Glasgow, $n$ (\%) } & \multirow[t]{2}{*}{$p$-value } \\
\hline & $\leq 7$ & $>7$ & \\
\hline \multicolumn{4}{|c|}{ Hunt-Hess } \\
\hline \multicolumn{4}{|c|}{ Preoperative } \\
\hline I & $0(0.0)$ & $13(34.2)^{b}$ & \multirow[t]{5}{*}{$<0.001$} \\
\hline II & $0(0.0)$ & $17(44.7)^{\mathrm{b}}$ & \\
\hline III & $0(0.0)$ & $6(15.8)$ & \\
\hline IV & $6(66.7)^{\mathrm{b}}$ & $2(5.3)$ & \\
\hline V & $3(33.3)^{b}$ & $0(0.0)$ & \\
\hline \multicolumn{4}{|c|}{ Postoperative } \\
\hline I & $0(0.0)$ & $19(51.4)^{b}$ & \multirow[t]{5}{*}{$<0.001$} \\
\hline II & $0(0.0)$ & $3(8.1)$ & \\
\hline III & $0(0.0)$ & $12(32.4)^{b}$ & \\
\hline IV & $6(60.0)^{b}$ & $3(8.1)$ & \\
\hline V & $4(40.0)^{\mathrm{b}}$ & $0(0.0)$ & \\
\hline
\end{tabular}

†Value obtained after application of the test of reason and likelihood. ${ }^{\mathrm{b}} \mathrm{A}$ statistically Significant value $(p<0.05)$ after residue analysis. Source: Search data, 2019. 
Table 5 Correlation between arterial system affected versus Fisher scale

\begin{tabular}{|l|l|l|l|}
\hline \multirow{4}{*}{} & \multicolumn{2}{|l|}{$n$ p -value $^{\dagger}$} \\
\cline { 2 - 3 } & \multicolumn{2}{|l}{ System } & \\
\cline { 2 - 3 } & Previous & Later & \\
\cline { 2 - 3 } & $n=41$ & $n=6$ & 0.268 \\
\hline Fisher & $6(14.6)$ & $2(33.3)$ & \\
\hline I & $11(26.8)$ & $0(0.0)$ & \\
\hline II & $6(14.6)$ & $1(16.7)$ & \\
\hline III & $18(43.9)$ & $3(50.0)$ & \\
\hline IV & &
\end{tabular}

†Value obtained after application of the test of reason and likelihood. Source: Search data, 2019.

mean age than non-hypertensive ones (57 and 49.91 years old, respectively), with a $p$-value of 0.01 . There is a statistical relationship between the average ages at the time of diagnosis of smokers with former smokers and nonsmokers in different analyzes. The average age of smokers is lower than the average age of former smokers (57 and 64 years old, respectively) and higher than the average age of nonsmokers (57.00 and 51.59 years, respectively). Both were measured by the Fisher LSD-test post hoc $(p<0.05)$. In addition, there is a relationship between gender and age at the moment of aneurysm diagnosis, where women have a higher average age than men (55.20 and 48.67 years old, respectively), with $p=0.041$ ( - Table 6).

Table 6 Correlation of the mean age of patients with systemic arterial hypertension, smoking and sex

\begin{tabular}{|l|l|l|l|}
\hline & $\mathbf{n}$ & Mean \pm SD & p-value \\
\cline { 3 - 3 } & & Age (years) & \\
\hline HAS & $0.010^{\dagger}$ \\
\hline Yes & 24 & $57.00 \pm 9.43$ & \\
\hline No & 23 & $49.91 \pm 8.64$ & \multirow{2}{*}{$0.041^{1^{\dagger \dagger}}$} \\
\hline Smoking & 10 & $57.00 \pm 9.78^{\mathrm{a}, \mathrm{b}}$ & \\
\hline Yes & 34 & $51.59 \pm 9.09^{\mathrm{a}}$ & \\
\hline No & 3 & $64.00 \pm 7.56^{\mathrm{b}}$ & \\
\hline Ex & \multicolumn{3}{|l}{$0.041^{\dagger}$} \\
\hline Gender & 35 & $55.20 \pm 8.16$ & \\
\hline Female & 35 & $48.67 \pm 9.65$ & \\
\hline Male & 12 &
\end{tabular}

Abbreviations: SD, standard deviation; HAS, systemic arterial hypertension.

${ }^{\dagger}$ Value obtained after applying the Student t-test for independent samples.

\#Value obtained after applying the one-way ANOVA test.

a, bDistinct letters represent significant differences after applying the Fisher LSD-test post hoc $(p<0.05)$.

Source: Search data, 2019.

\section{Discussion}

The present study found an average age of $53.53 \pm 9.64$ years old, which is equivalent to the mean age of patients undergoing cerebral aneurysm surgery found in several studies. According to the study by Rahmanian et al, ${ }^{14}$ among the 421 patients studied, an average of $49.8 \pm 1.5$ years old was found. According to a 2018 study, analyzing 2,898 patients, obtained an average of $58.9 \pm 14.3$ years old. ${ }^{15}$ According to the International Study on Unruptured Intracranial Aneurysms (ISUIA) trial, an average of $51.5 \pm 11.4$ years was obtained in patients undergoing surgery and, according to a study of 2019 , a mean age of $55.0 \pm 11.6$ years was obtained. ${ }^{17}$ The literature shows that patients with a more advanced age have a greater chance of developing the disease, perhaps due to comorbidities and time of evolution, such as hypertension and smoking. ${ }^{18}$

Regarding the most affected gender, we found a prevalence of $74.5 \%$ of women in our study. The ISUIA trial also showed a higher prevalence of females, with $75.9 \%$ of cases undergoing surgery. ${ }^{16}$ Out of the 2,898 patients analyzed by Oh et $a{ }^{15}{ }^{15} 73.2 \%$ were female. According to the study by Zheng et al, ${ }^{17}$ women corresponded to $50.92 \%$ of the affected patients. According to a 2018 publication, the female population under analysis corresponded to $74.0 \%{ }^{19}$ Comparing the data with the literature, the present study demonstrates prevalence of cerebral aneurysm in females. Therefore, in general, the literature shows that women are more affected by cerebral aneurysm. Perhaps women are more diagnosed with aneurysm because of their higher prevalence of SAH, with a ratio of $2: 1 .^{18}$

On the other hand, the present study showed that men tend to have earlier diagnosis compared with women. This fact has also been observed on the studies made by Ghods et al. ${ }^{20}$ This can be explained by the relationship between the pathophysiology of aneurysmal formation and female hormones, which are closely linked with hemodynamic stress and vascular remodeling induced by estrogen decline.

Regarding the presence of hypertension, the prevalence was $51.1 \%$ among the patients analyzed. According to a 2017 study, hypertension was observed in $47.1 \%$ of its patients. ${ }^{14}$ In a study published in 2019, hypertensive patients corresponded to $43.82 \%$ of the sample. ${ }^{17}$ A 2018 study showed that $31.2 \%$ were hypertensive. ${ }^{15}$ It is well described in the literature that hypertension can lead to cerebral aneurysm formation. ${ }^{18}$ The findings of the present study reinforce the importance of hypertension as a risk factor for cerebral aneurysm.

Regarding smoking, in the present study, a prevalence of $21.3 \%$ of patients undergoing brain aneurysm surgery was found. In the ISUIA trial, $47.2 \%$ of the patients were smokers, ${ }^{16}$ whereas, in another study, $29 \%$ of them were classified as smokers. ${ }^{14}$ In the study by Zheng et al, ${ }^{17} 30.25 \%$ of the patients were considered smokers. Still, according to Oh et $\mathrm{al}^{15}{ }^{15} 22.3 \%$ were smokers. In the sample by Bir et al, ${ }^{19} 50.4 \%$ were smokers. According to a 2015 study, smoking is an independent risk factor for the formation and growth of brain aneurysms. ${ }^{21}$ 
Furthermore, it was observed in the present study that the diagnosis was delayed in current smokers compared with nonsmokers. In contrast, according to $\mathrm{Ho}$ et $\mathrm{al}^{22}$ in their study, smokers were diagnosed earlier than nonsmokers. This discrepancy between studies can be explained, at least in part, by the fact that in the present study the number of smokers was small.

When analyzing the size of the aneurysms, $65.9 \%$ of the cases presented aneurysms between 2 and $7 \mathrm{~mm}$, and $21.3 \%$ presented aneurysms between 7 and $12 \mathrm{~mm}$. Compared with the ISUIA trial, it had a higher prevalence between 7 and $12 \mathrm{~mm}$ followed by those between 2 and $7 \mathrm{~mm} .{ }^{16}$ The study by Zheng et $\mathrm{al}^{17}$ found a higher prevalence of aneurysms $<12 \mathrm{~mm}$. These data corroborate the information that small aneurysms are the most prevalent ones. Thus, our study proved to be within the expected pattern. From the results found, it may be suggested that the size of the aneurysm found may be attributed to the age at which the diagnosis is made, the possibility of being incidental findings, technological advancement, which allows the diagnosis of smaller and smaller lesions, and the risk factors associated with aneurysm.

In the present study, the carotid system presented a larger number of patients, as well as the middle cerebral artery. Comparing with the literature, we see that the ISUIA trial ${ }^{16}$ observed the middle cerebral artery as the second most affected vessel. According to a study from 2018, the anterior circulation was the most affected system. ${ }^{15}$ Also, according to a study published in 2019, the carotid was the most affected system. ${ }^{17}$ According to Rahmanian et $\mathrm{al}^{14}$ the anterior system was the most affected, and the middle cerebral artery was the most frequently affected vessel. It was not possible to find in the current literature a pathophysiological correlation that can demonstrate a higher frequency of involvement of the anterior circulation. Even so, the data obtained in the present study follow the current literature.

Through statistical analysis, it can be demonstrated that there is a statistical correlation between the HH scale and the GCS. Patients with preoperative status classified as GCS $\leq 7$ had a worse HH grade (IV or V), whereas those with a GCS $>7$ had a better HH grade (I or II). With these results, we can suggest that further studies are performed so that in the future the GCS can be a complement to the assessment of the patient, helping in the surgical decision. No studies were found in the literature correlating the $\mathrm{HH}$ scale and the GCS.

\section{Study Limitations}

As a retrospective study based on secondary data analysis, the present research has some limitations. The sample had only white self-declared patients and the small sample size may have influenced the statistical analysis, requiring more studies to establish a better analysis of the epidemiological profile of patients undergoing brain aneurysm microsurgery in public and private services at the city of Criciúma, state of Santa Catarina, Brazil.

\section{Conclusion}

The present study concluded that traditional risk factors were present as expected in the analyzed sample. There is a prevalence of middle-aged women, a strong correlation between smoking and hypertension in the profile of cerebral aneurysm patients who underwent surgery. It was also observed that patients who underwent microsurgery with a significant decrease in level of consciousness had a significant correlation with a higher $\mathrm{HH}$ score.

Conflict of Interests

The authors have no conflict of interests to declare.

\section{References}

1 Lotufo PA, Goulart AC, Passos VMA, et al. Doença cerebrovascular no Brasil de 1990 a 2015: Global Burden of Disease 2015. Rev Bras Epidemiol 2017;20(20, Suppl 1):129-141

2 Pontes-Neto OM, Oliveira-Filho J, Valiente R, et al; Comitê Executivo da Sociedade Brasileira de Doenças Cerebrovasculares; Departamento Científico de Doenças Cerebrovasculares, Academia Brasileira de Neurologia. Diretrizes para o manejo de pacientes com hemorragia intraparenquimatosa cerebral espontânea. Arq Neuropsiquiatr 2009;67(3B):940-950

3 Vlak MHM, Algra A, Brandenburg R, Rinkel GJE. Prevalence of unruptured intracranial aneurysms, with emphasis on sex, age, comorbidity, country, and time period: a systematic review and meta-analysis. Lancet Neurol 2011;10(07):626-636

4 D'Souza S. Aneurysmal Subarachnoid Hemorrhage. J Neurosurg Anesthesiol 2015;27(03):222-240

5 Boulouis G, Rodriguez-Régent C, Rasolonjatovo EC, et al. Unruptured intracranial aneurysms: An updated review of current concepts for risk factors, detection and management. Rev Neurol (Paris) 2017;173(09):542-551

6 Lawton MT, Vates GE. Subarachnoid Hemorrhage. N Engl J Med 2017;377(03):257-266

7 Steiner T, Juvela S, Unterberg A, Jung C. Forsting, Rinkel G. European Stroke Organization Guidelines for the Management of Intracranial Aneurysms and Subarachnoid Haemorrhage. Cerebrovasc Dis 2013;35:93-112

8 Zhao J, Lin H, Summers R, Yang M, Cousins BG, Tsui J. Current Treatment Strategies for Intracranial Aneurysms: An Overview. Angiology 2018;69(01):17-30

9 de Rooij NK, Linn FHH, van der Plas JA, Algra A, Rinkel GJE. Incidence of subarachnoid haemorrhage: a systematic review with emphasis on region, age, gender and time trends. J Neurol Neurosurg Psychiatry 2007;78(12):1365-1372

10 Yoon NK, McNally S, Taussky P, Park MS. Imaging of cerebral aneurysms: a clinical perspective. Neurovasc Imaging 2016;2:1-7

11 Hunt WE, Hess RM. Surgical risk as related to time of intervention in the repair of intracranial aneurysms. J Neurosurg 1968;28(01): 14-20

12 Greenberg MS. Handbook of Neurosurgery. 8. ed. New York: Thieme; 2016:1664

13 Spetzler RF, McDougall CG, Zabramski JM, et al. Ten-year analysis of saccular aneurysms in the Barrow Ruptured Aneurysm Trial. J Neurosurg 2019;1:1-6

14 Rahmanian A, Jamali M, Bagheri Lankarani K, Ghahramani S. Aneurysmal subarachnoid haemorrhage (aSAH): Five consecutive years' experience of Fars province, Iran. PLoS One 2017;12(11): e0189005

15 Oh SY, Lim YC, Shim YS, et al. Initial misdiagnosis of aneurysmal subarachnoid hemorrhage: associating factors and its prognosis. Acta Neurochir (Wien) 2018;160(06):1105-1113 
16 Wiebers DO, Whisnant JP, Huston J III, et al; International Study of Unruptured Intracranial Aneurysms Investigators. Unruptured intracranial aneurysms: natural history, clinical outcome, and risks of surgical and endovascular treatment. Lancet 2003;362 (9378):103-110

17 Zheng K, Zhong M, Zhao B, et al. Poor-Grade Aneurysmal Subarachnoid Hemorrhage: Risk Factors Affecting Clinical Outcomes in Intracranial Aneurysm Patients in a Multi-Center Study. Front Neurol 2019;10:123

18 Ajiboye N, Chalouhi N, Starke RM, Zanaty M, Bell R. Unruptured cerebral aneurysms: evaluation and management. ScientificWorldJournal 2015;2015:954954. Doi: 10.1155/2015/954954
19 Bir SC, Nanda A, Cuellar H, et al. Coexistence of obstructive sleep apnea worsens the overall outcome of intracranial aneurysm: a pioneer study. J Neurosurg 2018;128(03):735-746

20 Ghods AJ, Lopes D, Chen M. Gender differences in cerebral aneurysm location. Front Neurol 2012;3:78

21 Davis MC, Broadwater DR, Amburgy JW, Harrigan MR. The clinical significance and reliability of self-reported smoking status in patients with intracranial aneurysms: a review. Clin Neurol Neurosurg 2015;137:44-49

22 Ho AL, Lin N, Frerichs KU, Du R. Smoking and Intracranial Aneurysm Morphology. Neurosurgery 2015;77(01):59-66, discussion 66 